\title{
ALTO DESEMPENHO NA PROTEÇÃO DIFERENCIAL DE TRANSFORMADORES DE POTÊNCIA COM A UTILIZAÇÃO DE REDES NEURAIS ARTIFICIAIS
}

\author{
Ê. C. Segatto* \\ segatto@sel.eesc.sc.usp.br \\ M. C. Tavares* \\ cristina@sel.eesc.sc.usp.br
}

\author{
D. V. Coury* \\ coury@sel.eesc.sc.usp.br \\ P. E. G. Campos* \\ guidetti@sel.eesc.sc.usp.br
}

${ }^{*}$ Dept $^{o}$ de Engenharia Elétrica, Universidade de São Paulo

Av. Dr. Carlos de Botelho, 1465, São Carlos (SP) - Brasil

\begin{abstract}
This paper presents an alternative approach using the differential logic associated to Artificial Neural Networks for protection of power transformers. Neural networks are used for distinguishing internal faults from inrush currents produced during the transformer energization. The EMTP-ATP software has been chosen as the computational tool to simulate the power transformer in order to generate data to train and test the ANNs. A complete differential protection software was implemented in FORTRAN and encouraging results related to the application of the new method are presented.
\end{abstract}

KEYWORDS: System Protection, Power Transformers, Differential Protection, Artificial Neural Networks (ANNs)

\section{RESUMO}

Este trabalho apresenta uma técnica alternativa para a proteção de transformadores de potência utilizando a lógica diferencial associada ao uso de Redes Neurais Artificiais (RNAs). Este artifício é utilizado na distinção

Artigo submetido em 9/2/2001

1a. Revisão em $7 / 11 / 2001$; 2a. Revisão em 8/8/2002;

3a. Revisão em 25/9/2002

Aceito sob recomendação do Ed. Assoc. Prof. Denizar C. Martins entre faltas internas e correntes de inrush, que surgem durante a energização do transformador. O programa EMTP-ATP (Electromagnetic Transients Program) foi escolhido como ferramenta computacional para a simulação do transformador de potência com o objetivo de gerar dados de treinamento e testes para as RNAs. Um programa em linguagem FORTRAN foi implementado a fim de avaliar o algoritmo completo da proteção diferencial e resultados promissores relativos ao novo método foram obtidos.

PALAVRAS-CHAVE: Proteção de Sistemas Elétricos, Transformadores de Potência, Proteção Diferencial, Redes Neurais Artificiais (RNAs)

\section{INTRODUÇÃO}

Os transformadores de potência são dispositivos que requerem manutenção e cuidados especiais devido à sua importância para o sistema elétrico no qual eles estão conectados. Geralmente, relés diferenciais são utilizados na proteção primária de transformadores de grande porte. Nestes relés, correntes diferenciais são comparadas a um patamar preestabelecido e, no caso de uma falta interna, o transformador deve ser desconectado do resto do sistema. Entretanto, a simples detecção de uma corrente diferencial não é suficiente para distinguir faltas 
internas de outras situações que também produzem tais correntes. Algumas destas situações surgem durante a energização do transformador (correntes de inrush), saturação dos TCs (transformadores de corrente), dentre outras ( Horowitz e Phadke, 1992; Bertrand et alii, 1997; Ling e Basak, 1989; Sidhu e Sachdev, 1992), as quais podem originar um incorreto acionamento do disjuntor correspondente. A correta e rápida distinção entre faltas internas e algumas das situações mencionadas consiste em um dos desafios para a atual proteção de transformadores de potência. O método tradicionalmente usado para esta finalidade é a lógica diferencial com restrição harmônica (Rahman e Jeyasurya, 1988). Neste método, a situação de inrush no transformador devido à operação de energização é reconhecida com base no conteúdo do componente de $2^{a}$ harmônica (acima de $16 \%$ ) obtido por filtros (Nagpal et alii, 1995; Liu et alii, 1992). Entretanto, este processo pode, em algumas vezes, atrasar a operação da proteção. Além disso, componentes de $2^{a}$ harmônica podem também estar presentes durante faltas internas (Pihler et alii, 1997; Kolla, 1995).

Novos métodos têm sido estudados nos últimos anos, buscando um melhoramento na seletividade, sensibilidade e operação de relés diferenciais, tais como as Redes Neurais Artificiais (RNAs) e a lógica Fuzzy. Diferentes arquiteturas são apresentadas na literatura com bons resultados (Mao et alii, 1998; Bastard et alii, 1995; Perez et alii, 1994).

Este trabalho apresenta um método alternativo utilizando a lógica diferencial associada às Redes Neurais Artificiais com o objetivo de melhorar o desempenho da proteção de transformadores de potência. Em relação à arquitetura proposta, pôde ser observado um melhoramento na capacidade de distinção entre correntes provenientes de faltas internas e de magnetização (inrush), bem como na velocidade de resposta, se comparadas aos métodos similares existentes na literatura. Neste trabalho, o EMTP-ATP é usado no modelamento do transformador para a geração de dados empregados no treinamento e testes das redes neurais. Resultados bastante encorajadores relativos à nova metodologia são apresentados.

\section{A PROTEÇÃO DIFERENCIAL PER- CENTUAL}

Como mencionado anteriormente, a lógica diferencial é utilizada na proteção de grandes transformadores de potência e a mesma é ilustrada na figura 1 a seguir. A ilustração também mostra a conexão dos TCs aos ramos primário e secundário do transformador. N1:N2 é a relação de espiras entre os enrolamentos primário e se-

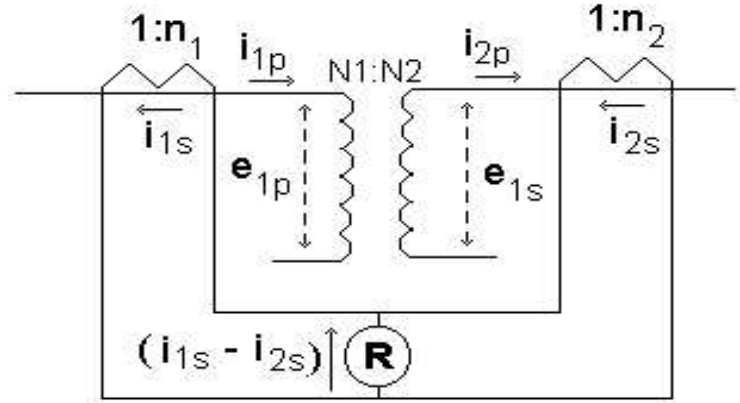

Figura 1: Diagrama do transformador monofásico, com conexão do relé de proteção diferencial

cundário do transformador e $1: \mathrm{n}_{1}$ e $1: \mathrm{n}_{2}$ são as relações de espiras entre os ramos e os TCs, selecionados para fazer $\mathrm{N} 1 \mathrm{n}_{1}=\mathrm{N} 2 \mathrm{n}_{2}$. Sob condições normais e de faltas externas a um transformador monofásico, as correntes $\mathrm{i}_{1 S}$ e $\mathrm{i}_{2 S}$ (correntes secundárias dos TCs) são iguais.

Porém, no caso de faltas internas, a diferença entre estas correntes torna-se significativa, causando a atuação do relé de sobrecorrente. Portanto, a corrente diferencial

$$
i_{d}=i_{1 S}-i_{2 S}
$$

fornece uma medida precisa da corrente de falta.

A fim de corrigir erros introduzidos pelos TCs e pelas mudanças de tap do transformador, um patamar é fixado para que uma pequena corrente diferencial possa ser tolerada, sem desconectar o sistema (Grcar e Dolinar, 1994). Essa relação é mostrada na equação 2.

$$
i_{d} \geq K .\left(i_{1 S}+i_{2 S}\right) / 2
$$

onde $\mathrm{K}$ é a inclinação da característica diferencial.

A figura 2 mostra a característica diferencial do relé incluindo as zonas de operação e restrição. São apresentados alguns ajustes para K (15\%, 25\% e 40\%). CO' é um patamar usado quando uma condição de sobrexcitação é detectada.

Como já citado, certos fenômenos podem causar uma corrente diferencial considerável, mesmo sem existir uma situação de falta e estes falsos sinais são geralmente suficientes para causar o acionamento do relé. Entretanto, nestes casos, a proteção diferencial não deveria desconectar o sistema porque uma falta interna não estaria caracterizada.

A seguir é descrita uma das principais situações geradoras deste problema. 


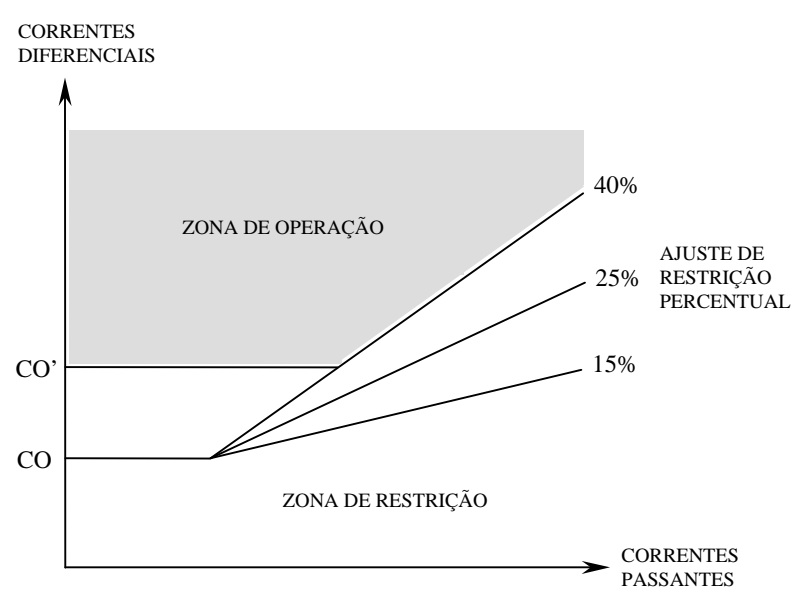

Figura 2: Característica diferencial percentual

\subsection{Corrente de Magnetização na Energi- zação}

Correntes de magnetização (inrush) surgem durante a energização do transformador devido à magnetização e saturação de seu núcleo. A declividade da característica de magnetização na área saturada determina sua magnitude. Em transformadores modernos, altas correntes de inrush podem surgir (Horowitz e Phadke, 1992; Verma e Basha, 1986). Como o lado secundário está aberto na energização do transformador, a corrente diferencial pode alcançar valores suficientemente altos, originando uma operação indevida do relé. A modelagem de tal situação tem sido estudada, mostrando a predominância do componente de $2^{a}$ harmônica.

Alguns outros fenômenos que podem originar falsas correntes diferenciais são correntes de magnetização ocorridas mediante a remoção de uma falta externa, sobrexcitação do transformador e saturação dos TCs.

\section{REDES NEURAIS ARTIFICIAIS}

A rede de neurônios artificiais foi inspirada no pouco que o homem já conhece sobre o cérebro humano. O mesmo possui as características de robustez, tolerância à falhas, capacidade de ajuste a novos ambientes pelo treinamento, potencial para processar informações ruidosas, além de alta velocidade de processamento. As transmissões e recepções entre neurônios acontecem por aumento ou diminuição do potencial elétrico na célula receptora. O primeiro modelo artificial de um neurônio biológico foi fruto do trabalho pioneiro de Warren McCulloch e Walter Pitts (McCulloch e Pitts, 1943). No trabalho publicado em 1943, foi apresentada uma discus- são sofisticada de redes lógicas de nodos, com atenção voltada para os métodos de aprendizado. O primeiro trabalho específico sobre o aprendizado de redes artificiais foi proposto por Donald Hebb (Hebb, 1949). Hebb mostrou como a plasticidade da aprendizagem de redes neurais é conseguida através da variação dos pesos de entrada dos nodos, propondo uma teoria para explicar o aprendizado baseada no reforço das ligações entre os nós excitados. Mais tarde, Widrow e Hoff (Widrow e Hoff, 1960) sugeriram uma regra de aprendizado conhecida como regra delta, que é sustentada no método do gradiente para minimização do erro na saída de um neurônio com resposta linear. Em 1958, Frank Rosenblatt demonstrou seu modelo chamado Perceptron, no qual, se fossem acrescidas de ligações ajustáveis, as RNAs poderiam ser treinadas para classificar certos tipos de padrões, propondo ainda um algoritmo para treinar a rede e executar determinados tipos de funções (Rosenblatt, 1958). Em 1969, Minsky e Papert chamaram a atenção para algumas tarefas que os atuais modelos não eram capazes de realizar, já que só resolviam problemas linearmente separáveis, ou seja, problemas cuja solução pode ser obtida dividindo-se o espaço de entrada em duas regiões através de uma reta (Minsky e Papert, 1969). Nos anos 70, a abordagem conexionista ficou adormecida, com poucos pesquisadores trabalhando na área. Finalmente em 1982, John Hopfield publicou um artigo (Hopfield, 1982) que chamou a atenção das propriedades associativas das RNAs. Este trabalho foi responsável por parte da retomada das pesquisas na área. Não obstante, a descrição do algoritmo de treinamento Backpropagation alguns anos mais tarde (Rumelhart, Hinton e Williams, 1986), mostrou que as visões anteriores sobre o Perceptron eram bastante pessimistas. As RNAs de múltiplas camadas são, sem dúvida, capazes de resolver problemas "difíceis de aprender". A partir de meados da década de 80 houve nova explosão de interesse pelas redes neurais artificiais na comunidade internacional. Um outro fator foi responsável pela retomada de interesse na área: o avanço da tecnologia, que vem permitindo a realização física de modelos de nodos e sua interconexão de modo antes impensável. (Carvalho et alii, 1998)

Em relação ao funcionamento das RNAs, um modelo de neurônio artificial binário com limiar unitário foi portanto proposto inicialmente, no qual as entradas do neurônio são ponderadas pelos seus pesos com as saídas da célula anterior ou com os sinais de entrada da rede e que possui estado de ativação definido unicamente por uma função degrau. Mais tarde, implementou-se um modelo de RNA que consiste de um conjunto de células conectadas e com uma regra de propagação. Cada neurônio recebe suas entradas com os pesos associados, vindas de outros neurônios ou de estímulo externo. A 


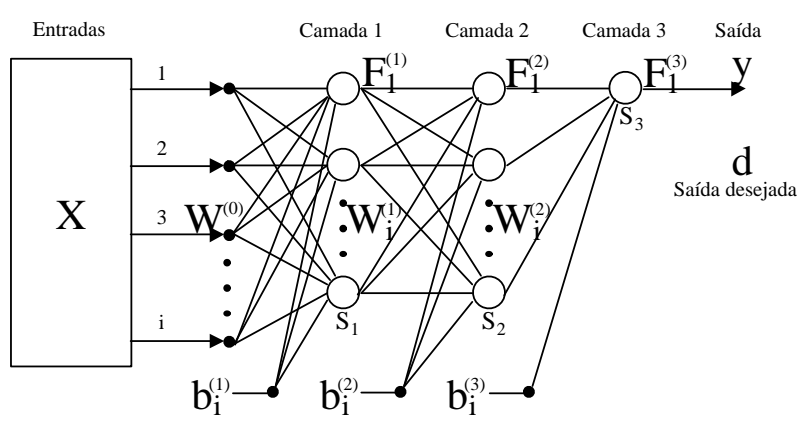

Figura 3: Rede Neural completa com três camadas

função de ativação é usualmente uma somatória agindo nas entradas da rede. Os valores bias de oposição são adicionados à somatória das entradas com pesos. O estado de ativação do neurônio é determinado pela função de saída ou de transferência e geralmente é uma função sigmodal. A saída do neurônio chega, pelas sinapses, até a próxima célula. Portanto, uma RNA completa é formada por um conjunto de neurônios dispostos em uma ou mais camadas, conectados por ligações de pesos variados. A rede Feedforward tem a propagação do sinal para frente, entre células de camadas adjacentes, até a última camada (saída) (SNNS User Manual, 1995). Na fase de treinamento da rede, há a determinação e a correção dos pesos e dos bias, para que a mesma responda de forma desejada. Uma rede neural completa é mostrada na figura 3.

A figura 3 mostra uma rede neural de três camadas, onde:

$X=$ vetor de dados de entrada

$W_{i}^{(m)}=$ matriz de valores de peso associados a cada entrada $i$ e a cada camada $m$

$F_{i}^{(m)}=$ função de transferência sigmoidal de cada unidade, associada a certa camada $m$

$$
F(h-b)=\frac{1}{1+e^{-(h-b) / 2}}
$$

$b_{i}^{(m)}=$ unidades bias

$d=$ saída desejada da rede para cada entrada

$y=$ saída fornecida pela rede neural para cada entrada

A entrada para um dado neurônio $i$, com seus pesos correspondentes de uma certa camada $m$, é definida como:

$$
h_{i}^{(m)}=\left[w_{i}^{(m)}\right] x^{(m)}=\Sigma_{k=1}^{M}\left(w_{i k}^{(m)} \cdot x^{(m)}\right)
$$

A saída do neurônio $i$ na camada $m$ é definida como:

$$
y_{i}^{(m)}=F_{i}\left(h_{i}-b_{i}\right)
$$

Ainda, $y^{(m)}=X^{(m+1)}$, ou seja, a entrada da próxima camada é a saída da camada anterior. Existe um vetor de saídas $y$ para cada vetor de entradas $X$. Os pesos $w$ e bias $b$ são atualizados para cada célula, até obterse o critério de parada do treinamento (erro aceitável alcançado). A RNA empregada utilizou o método de treinamento Backpropagation que realiza a busca por um erro aceitável.

Este erro é dado por:

$$
E_{p}=\frac{(d-y)^{2}}{2}
$$

Este valor é calculado para as células de saída da rede.

O objetivo deste algoritmo de treinamento é minimizar o erro de saída para cada vetor de entrada, ou seja, minimizar a distância quadrática entre as saídas desejadas e calculadas. A estrutura de processamento paralelo de informação permite a inclusão de conhecimento hábil no processo, a deteç̧ão e a classificação de sinais. A característica da RNA é, então, considerar o conhecimento adquirido durante o treinamento e responder a novos dados de entrada da maneira mais apropriada, concluindo assim, uma generalização do problema. A arquitetura da rede neural é definida pelos pesos correspondentes e esquema de conexões. Já o processo de aprendizagem envolve a mudança nos valores dos pesos, sendo o aspecto mais explorado em redes neurais artificiais.

\subsection{O Método Backpropagation}

O método de treinamento utilizado neste trabalho é denominado Backpropagation (Rumelhart e McClelland, 1986) e funciona pelo ajuste de valores de pesos que estão associados às conexões das sucessivas camadas de uma rede MLP (Multi-Layer Perceptrons) (Hertz et alii, 1991). O algoritmo fornece uma forma de definir o erro dos nodos das camadas intermediárias para a mudança nos pesos em uma rede feedforward (propagação dos sinais para frente). Esta rede é treinada através do fornecimento de padrões de entrada e de saída desejada. A maioria dos métodos de aprendizado para RNAs do tipo Perceptron de múltiplas camadas utilizam variações deste algoritmo. Embora a popularização deste procedimento tenha surgido a partir de 1986, ele foi proposto muito antes, com diferentes propósitos, por diferentes pesquisadores. (Bryson e Ho, 1969 ; Werbos, 1974 ; Parker, 1985 ; Le Cun, 1985).

O algoritmo Backpropagation é supervisionado, ou seja, a entrada e saída desejadas para a rede são fornecidas por um supervisor externo. O objetivo é, através de um mecanismo de correção de erros, ajustar os parâmetros 
(pesos) da rede, de forma a encontrar uma ligação entre os pares de entrada e saída fornecidos. O treinamento ocorre em duas fases, onde cada fase percorre a rede em um sentido. Estas duas fases são chamadas de forward e backward. A fase forward é utilizada para definir a saída da rede para um dado padrão de entrada. A fase backward utiliza a saída desejada e a saída fornecida pela rede para atualizar os pesos de suas conexões a cada iteração.

\section{O ALGORITMO DE PROTEÇÃO DIFE- RENCIAL PROPOSTO}

A figura 4 mostra o algoritmo proposto para o relé diferencial. O passo inicial do algoritmo calcula a corrente diferencial e verifica sua magnitude. Para tanto, a característica diferencial percentual do tipo apresentado na figura 2 é usada. Se uma corrente diferencial significativa é obtida, o algoritmo utiliza uma subrotina baseada em RNAs a fim de distinguir faltas internas de correntes de inrush. No caso da detecção de uma falta interna, um contador é incrementado e, após atingir um limite prefixado, é enviado um sinal de desligamento ao disjuntor.

Similarmente à detecção de correntes de inrush, a condição de sobrexcitação do transformador também pode ser detectada por RNAs. Esta subrotina está atualmente sendo implementada pelos autores.

\section{A SIMULAÇÃO DO SISTEMA ELÉ- TRICO}

\subsection{O Sistema Elétrico Utilizado}

A figura 5 mostra a representação do sistema elétrico simulado pelo programa EMTP-ATP (Coury et alii, 1998; Alternative Transients Program Rule Book, 1987; Kasztenny et alii, 1995).

O sistema é composto de um equivalente de geração de $138 \mathrm{kV}$ e 30 MVA, um transformador de $138 / 13,8 \mathrm{kV}$ e 25 MVA, uma linha de transmissão de $5 \mathrm{~km}$ seguida de uma carga de 10 MVA e fator de potência 0,92 indutivo.

O transformador trifásico é conectado em configuração delta/estrela e seu modelo no EMTP-ATP foi implementado utilizando-se três transformadores monofásicos.

O modelo utilizado para representar faltas internas é ilustrado na figura 6 . As simulações de falta são obtidas dividindo-se os enrolamentos e as impedâncias de acordo com as porções onde as faltas seriam aplicadas.

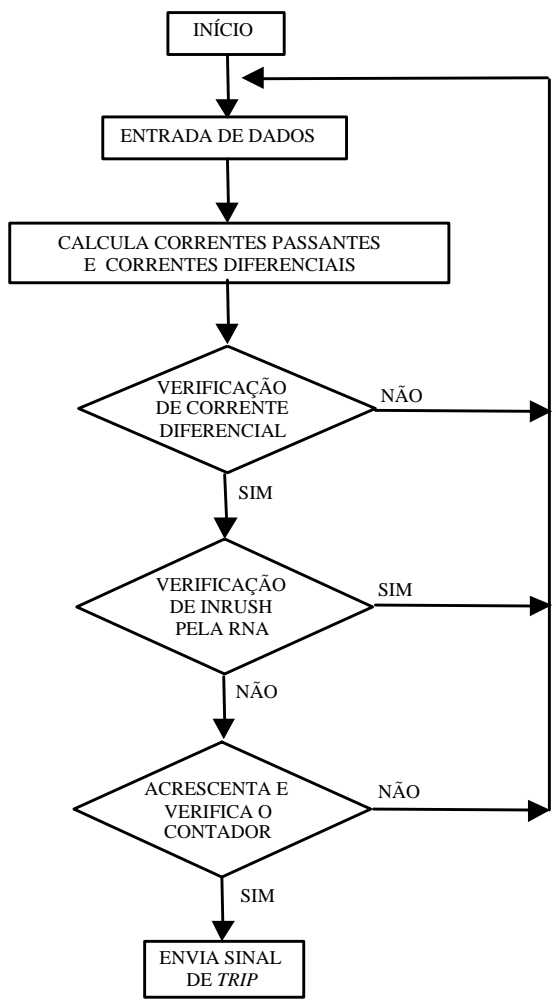

Figura 4: Algoritmo da proteção diferencial proposto usando RNAs.

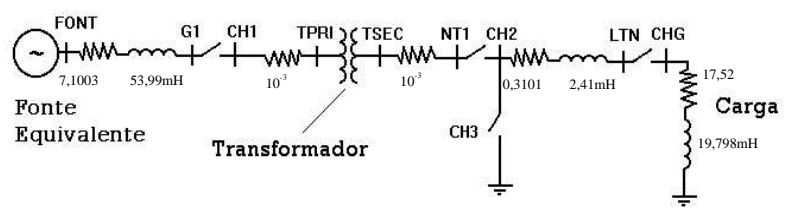

Figura 5: Sistema elétrico simulado no EMTP-ATP

A tabela 1 apresenta os valores relativos à curva de saturação utilizada na simulação do transformador de potência, fornecida pela CPFL - Companhia Paulista de Força e Luz, correspondente ao transformador utilizado.

A figura 7 e a figura 8 mostram as principais situações envolvidas no treinamento das RNAs. A figura 7 representa um caso de energização no qual o transformador é conectado em $6 \mathrm{~ms}$ nas três fases.

A figura 8 mostra uma falta interna em $10 \%$ do enrolamento do transformador ocorrida em $10 \mathrm{~ms}$ com carga de 10 MVA. Pode ser observado visualmente que as referidas ondas possuem características bastante distin- 


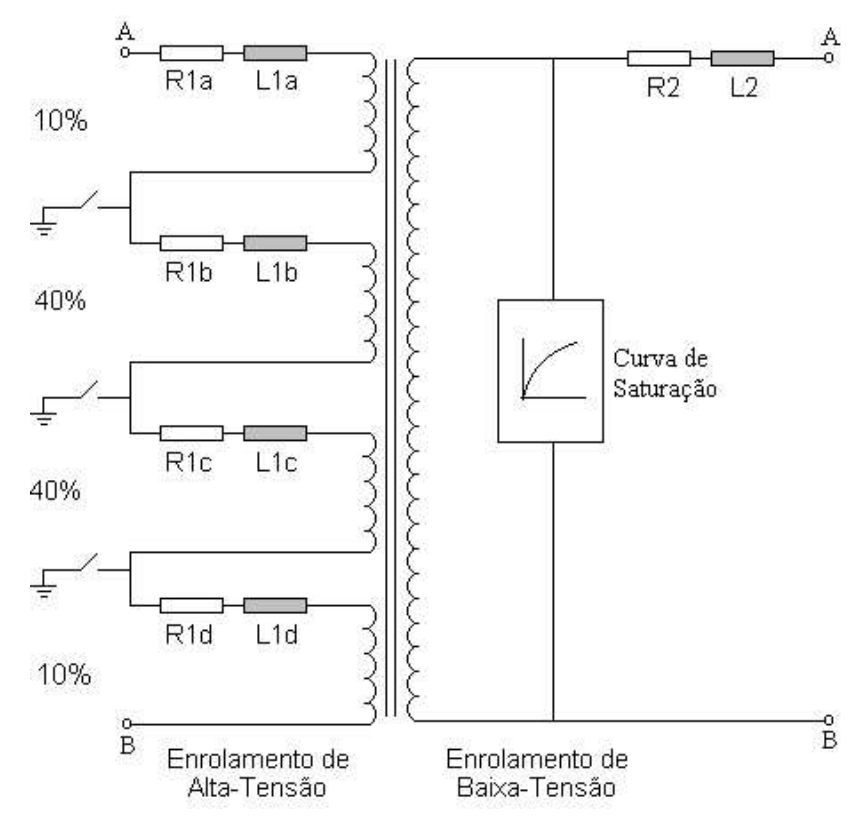

Figura 6: Conexão do enrolamento sob falta

Tabela 1: Valores de fluxo e corrente da curva de saturação do transformador

\begin{tabular}{|c|c|}
\hline Fluxo (V.s) & Corrente (A) \\
\hline 26,8995372 & 1,06055811 \\
29,8883747 & 3,28814356 \\
32,8772122 & 20,8489263 \\
34,3716309 & 129,055289 \\
35,2682821 & 380,764491 \\
\hline
\end{tabular}

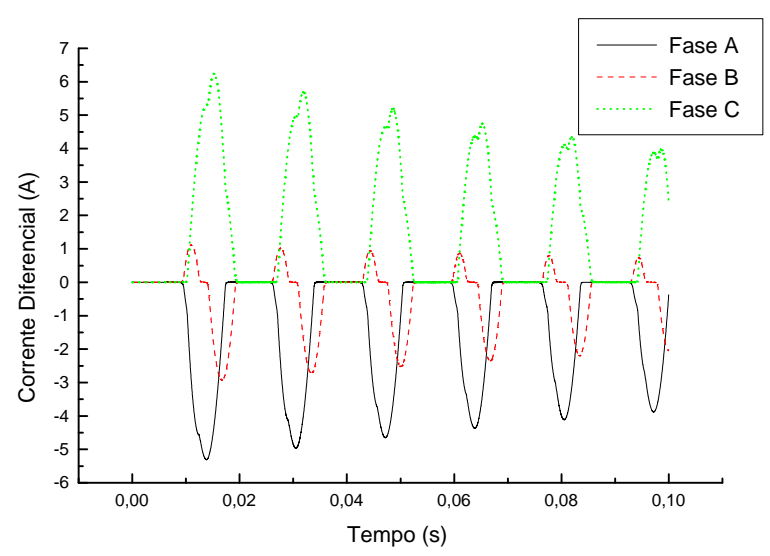

Figura 7: Conexão do enrolamento sob falta

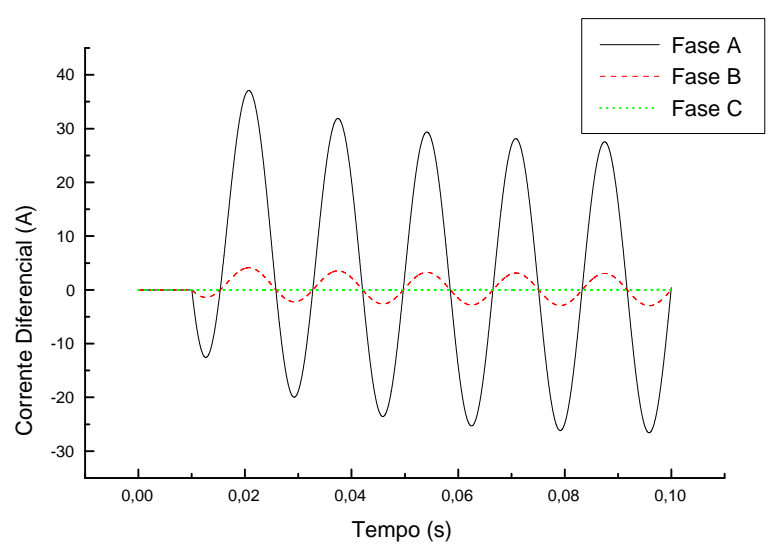

Figura 8: Casos de falta interna simulados

Tabela 2: Caso de falta interna simulado

\begin{tabular}{|c|c|c|c|}
\hline Tensão (kV) & Carga (MVA) & $\begin{array}{c}\text { \% do enrolamento } \\
\text { envolvido na } \\
\text { aplicação da falta }\end{array}$ & $\begin{array}{c}\text { Angulo de } \\
\text { Incepção (graus) }\end{array}$ \\
\hline 112,7 & 8,0 & 10 & 43,0 \\
115,0 & 10,0 & 30 & 65,0 \\
& 12,0 & 50 & 108,0 \\
& & 70 & 173,0 \\
& & 90 & 216,0 \\
& & & 238,0 \\
& & & 260,0 \\
& & & 281,0 \\
& & \multicolumn{2}{|c}{} \\
& & & 324,0 \\
\hline
\end{tabular}

tas, sendo muito propícia a utilização de RNAs para diferenciá-las.

A tabela 2 mostra a combinação de valores para os casos de falta interna simulados com o objetivo de treinar a RNA. A tabela 3 ilustra esta combinação para os casos de energização. Um total de 270 casos foram simulados para cada situação.

Após o processo de simulação no programa EMTP-ATP, os dados foram organizados a fim de serem empregados na etapa de treinamento, descrito mais detalhadamente na próxima seção.

Deve ser mencionado ainda, que casos de falta externa, remoção de falta externa e rejeição de carga também foram simulados com o objetivo de testar o algoritmo proposto. Os resultados são apresentados na seção 7 . 
Tabela 3: Casos de energização simulados

\begin{tabular}{|c|c|c|c|}
\hline \multirow{2}{*}{ Tensão $(\mathrm{kV})$} & \multicolumn{3}{|c|}{ Instante de } \\
& fechamento das chaves $(\mathrm{ms})$ \\
\cline { 2 - 4 } & Fase A & Fase B & Fase C \\
\hline 107,0 & 6 & 6 & 6 \\
108,0 & 6 & 6 & 10 \\
109,0 & 6 & 7 & 6 \\
109,5 & 6 & 7 & 10 \\
110,0 & 6 & 9 & 12 \\
111,0 & 6 & 11 & 15 \\
112,7 & 7 & 9 & 11 \\
113,3 & 7 & 11 & 7 \\
114,0 & 7 & 11 & 12 \\
115,0 & 7 & 6 & 9 \\
115,5 & 7 & 7 & 6 \\
116,0 & 7 & 7 & 7 \\
116,5 & 9 & 9 & 13 \\
117,0 & 9 & 10 & 13 \\
118,0 & 9 & 6 & 6 \\
& 9 & 9 & 12 \\
& 9 & 7 & 10 \\
& 9 & 11 & 7 \\
\hline
\end{tabular}

\section{A REDE NEURAL ARTIFICIAL DISTIN- GUINDO FALTAS INTERNAS DE COR- RENTES DE INRUSH}

O programa SNNS - Stuttgart Neural Network Simulator (SNNS User Manual, 1995) foi utilizado para treinar e testar as diferentes arquiteturas, a fim de distinguir faltas internas de correntes de inrush. O SNNS foi escolhido devido à sua comprovada eficiência e simplicidade, bem como a amigável interface gráfica. O método de aprendizagem utilizado durante o treinamento da RNA foi o algoritmo Backpropagation com o termo Momentum.

A fórmula geral de correção de erros utilizada neste método é mostrada a seguir.

$$
\Delta w_{i j}(k+1)=\alpha \delta_{j}(k) y_{j}(k)+\mu \Delta w_{i j}(k)
$$

onde:

$\alpha=$ taxa de aprendizagem.

$\mu=$ termo Momentum, especifica o quanto o peso anterior é alterado, sendo adicionado à variação corrente.

$y_{j}=$ saída desejada para o neurônio $j$.

$\delta_{j}=$ erro para o neurônio $j$.

$\Delta w_{i j}=$ correção do peso entre o neurônio $i$ e o neurônio $j$.

$k=$ valor da iteração.

\subsection{O Processo de Treinamento}

Após a simulação dos dados, estes foram divididos em conjuntos de treinamento, validação e testes. Um total de quatro amostras por fase das correntes diferenciais foram utilizadas no treinamento com freqüência amostral de $1 \mathrm{kHz}$. Ainda, para cada fase, uma janela de dados móveis foi empregada. Aos casos de faltas internas, associou-se a saída 1,0 e aos casos de correntes de inrush, a saída 0,0 .

As três janelas de dados móveis para a fase A são: Primeira janela $-i_{A 1}, i_{A 2}, i_{A 3}, i_{A 4}$

Segunda janela $-i_{A 2}, i_{A 3}, i_{A 4}, i_{A 5}$

Terceira janela $-i_{A 3}, i_{A 4}, i_{A 5}, i_{A 6}$

onde $i_{A 1}, i_{A 2}, i_{A 3}, i_{A 4}, i_{A 5}$ e $i_{A 6}$ são os valores discretos de corrente diferencial da fase $\mathrm{A}$.

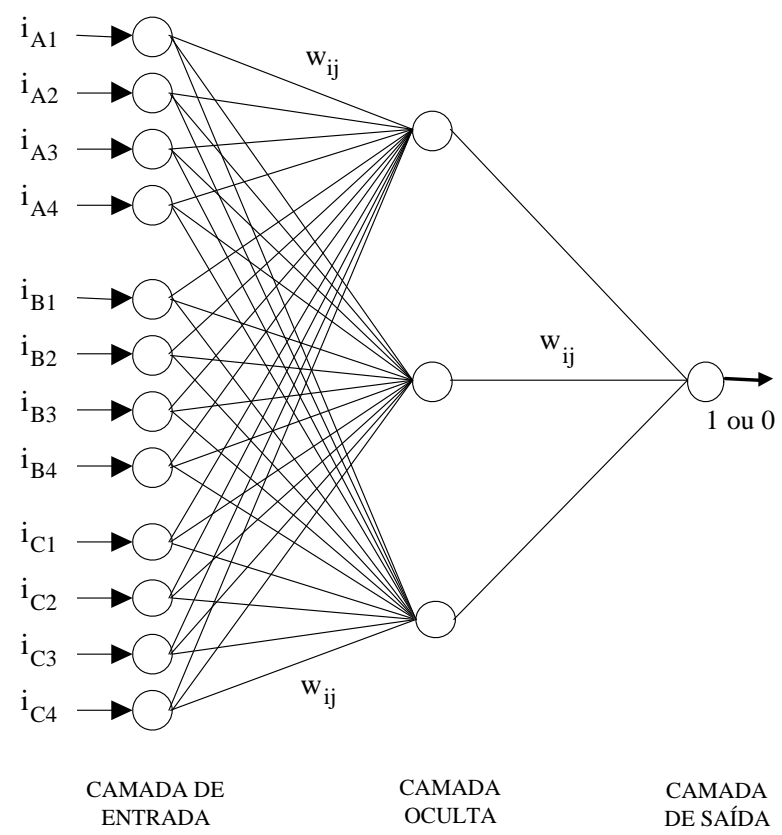

Figura 9: Arquitetura de RNA testada

O procedimento é similar para as fases B e C. Um total de 1620 padrões de entrada (540x3 janelas) foram simuladas para o treinamento da rede neural, onde 810 casos correspondem a faltas internas e outros 810 correspondem a situações de energização.

Várias topologias diferentes de redes MLP foram treinadas e testadas e será apresentada aqui a melhor arquitetura obtida, de configuração $12+3+1$. Esta arquitetura possui 12 neurônios na primeira camada (12 sinais de entrada de corrente em cada padrão), 3 neurônios na camada oculta e 1 neurônio na camada de saída, como mostrado na figura 9. O processo de aprendizagem convergiu em aproximadamente 20000 ciclos. Este procedimento de treinamento é executado apenas uma vez e uma capacidade de generalização da RNA é esperada. 
O termo Momentum foi mantido em 0,1 e o erro quadrático médio não ultrapassou o valor 0,00052 .

Com relação às saídas da RNA, valores entre 0,0 e 0,1 foram associados às situações de energização do transformador, enquanto valores entre 0,9 e 1,0 foram associados aos casos de falta interna.

\subsection{Resultados Obtidos}

A figura 10 mostra o gráfico de respostas da camada de saída da rede, para 810 padrões testados, fornecendo valores zero ou um, dependendo da situação testada. É importante salientar que os 810 padrões utilizados nos testes das RNAs não foram empregados na etapa de treinamento das mesmas.

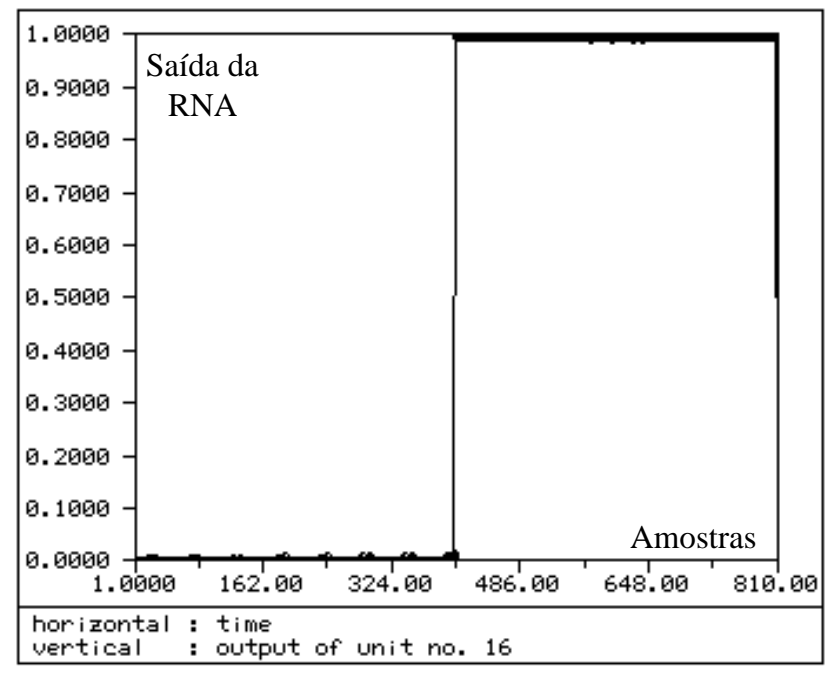

Figura 10: Gráfico de saída para a arquitetura $12+3+1$ em 810 casos testados

Deve ser notado que, da amostra número 1 até a amostra número 405, a rede apresenta resultados menores que 0,1 porque este intervalo contém dados de energização. Por outro lado, da amostra número 406 à amostra número 810 , os valores são muito próximos a 1 , devido a este intervalo conter dados de falta interna. A rede neural analisada confirmou a correta classificação de todos os padrões testados.

As tabelas 4, 5, 6 e 7 também indicam a eficiência do método. Com relação aos dados de energização do transformador, a tabela 4 e a tabela 5 indicam as saídas da RNA para diferentes tempos de fechamento das chaves relativas às fases, bem como para diferentes tensões de operação. Nota-se nesses resultados, que as respostas fornecidas pela RNA foram bem próximos ao valor 0 (zero), o valor esperado para a saída da rede neural nos
Tabela 4: Saída da RNA para casos de energização do transformador $(113,3-115,5 \mathrm{kV})$

\begin{tabular}{|c|c|c|c|c|c|c|c|}
\hline \multirow{2}{*}{\multicolumn{3}{|c|}{$\begin{array}{c}\text { INSTANTE DE } \\
\text { FECHAMENTC } \\
\text { DAS CHAVES } \\
(\mathrm{ms})\end{array}$}} & $\begin{array}{c}\text { JANELA } \\
\text { DE }\end{array}$ & \multirow{2}{*}{\multicolumn{4}{|c|}{ TENSÃO (kV) }} \\
\hline & & & \multirow[t]{3}{*}{$\begin{array}{l}\text { DADOS } \\
\text { MÓVEIS }\end{array}$} & & & & \\
\hline \multicolumn{3}{|c|}{ FASES } & & 113,3 & 114,0 & 115,0 & 115,5 \\
\hline A & B & $\mathrm{C}$ & & Resposta Obtida & Resposta Obtida & Resposta Obtida & Resposta Obtida \\
\hline \multirow{3}{*}{7} & \multirow{3}{*}{6} & \multirow{3}{*}{9} & $1^{\mathrm{a}}$ & 0,000066 & 0,000064 & 0,000062 & 0,000061 \\
\hline & & & $2^{a}$ & 0,000071 & 0,000069 & 0,000067 & 0,000066 \\
\hline & & & $3^{\mathrm{a}}$ & 0,000101 & 0,000099 & 0,000096 & 0,000094 \\
\hline \multirow{3}{*}{7} & \multirow{3}{*}{7} & \multirow{3}{*}{6} & $1^{\mathrm{a}}$ & 0,001223 & 0,001240 & 0,001269 & 0,001287 \\
\hline & & & $2^{a}$ & 0,001349 & 0,001383 & 0,001431 & 0,001465 \\
\hline & & & $3^{\mathrm{a}}$ & 0,001093 & 0,001127 & 0,001183 & 0,001220 \\
\hline \multirow{3}{*}{7} & \multirow{3}{*}{7} & \multirow{3}{*}{7} & $1^{\mathrm{a}}$ & 0,000331 & 0,000326 & 0,000317 & 0,000314 \\
\hline & & & $2^{\mathrm{a}}$ & 0,000296 & 0,000300 & 0,000310 & 0,000313 \\
\hline & & & $3^{\mathrm{a}}$ & 0,000288 & 0,000290 & 0,000296 & 0,000298 \\
\hline \multirow{3}{*}{9} & \multirow{3}{*}{9} & \multirow{3}{*}{13} & $1^{\mathrm{a}}$ & 0,000871 & 0,000842 & 0,000809 & 0,000779 \\
\hline & & & $2^{a}$ & 0,000957 & 0,000939 & 0,000920 & 0,000910 \\
\hline & & & $3^{\mathrm{a}}$ & 0,000986 & 0,000974 & 0,000958 & 0,000956 \\
\hline \multirow{3}{*}{9} & \multirow{3}{*}{10} & \multirow{3}{*}{13} & $1^{\mathrm{a}}$ & 0,000819 & 0,000776 & 0,000714 & 0,000686 \\
\hline & & & $2^{a}$ & 0,000923 & 0,000906 & 0,000869 & 0,000856 \\
\hline & & & $3^{\mathrm{a}}$ & 0,000869 & 0,000855 & 0,000818 & 0,000806 \\
\hline \multirow{3}{*}{9} & \multirow{3}{*}{6} & \multirow{3}{*}{6} & $1^{\mathrm{a}}$ & 0,001425 & 0,001475 & 0,001551 & 0,001584 \\
\hline & & & $2^{\mathrm{a}}$ & 0,002734 & 0,002971 & 0,003343 & 0,003511 \\
\hline & & & $3^{\mathrm{a}}$ & 0,005711 & 0,006366 & 0,007434 & 0,007946 \\
\hline \multirow{3}{*}{9} & \multirow{3}{*}{9} & \multirow{3}{*}{12} & $1^{\mathrm{a}}$ & 0,000250 & 0,000238 & 0,000223 & 0,000214 \\
\hline & & & $2^{\mathrm{a}}$ & 0,000218 & 0,000207 & 0,000193 & 0,000185 \\
\hline & & & $3^{\mathrm{a}}$ & 0,000388 & 0,000376 & 0,000348 & 0,000330 \\
\hline \multirow{3}{*}{9} & \multirow{3}{*}{7} & \multirow{3}{*}{10} & $1^{\mathrm{a}}$ & 0,000896 & 0,000837 & 0,000789 & 0,000760 \\
\hline & & & $2^{a}$ & 0,000235 & 0,000222 & 0,000208 & 0,000200 \\
\hline & & & $3^{\mathrm{a}}$ & 0,000103 & 0,000098 & 0,000092 & 0,000089 \\
\hline \multirow{3}{*}{9} & \multirow{3}{*}{11} & & $1^{\mathrm{a}}$ & 0,005168 & 0,005719 & 0,006648 & 0,007084 \\
\hline & & 7 & $2^{\mathrm{a}}$ & 0,003796 & 0,004108 & 0,004708 & 0,004961 \\
\hline & & & $3^{\mathrm{a}}$ & 0,006485 & 0,007352 & 0,008892 & 0,009617 \\
\hline
\end{tabular}

casos de energização.

A tabela 6 e a tabela 7 ilustram as saídas da RNA para faltas internas em $10 \%$ e $90 \%$ do enrolamento do transformador respectivamente, para diferentes ângulos de incepção da falta e condições de falta. Nota-se nesses resultados, que as respostas fornecidas pela RNA foram bem próximos ao valor 1 (um), o valor esperado para a saída da rede neural nos casos de falta interna. Todas as tabelas apresentam também as saídas da rede para cada uma das três consecutivas janelas de dados móveis.

As redes neurais apresentaram $100 \%$ de precisão na distinção entre faltas internas e correntes inrush para os 810 casos testados.

\section{RESULTADOS GERAIS DO ESQUEMA PROPOSTO}

Para testar o esquema completo de proteção diferencial proposto, implementou-se um programa em linguagem FORTRAN, simulando o algoritmo do relé diferencial. O método utiliza a RNA para a discriminação do sinal 
Tabela 5: Saída da RNA para casos de energização do transformador $(116,0-118,0 \mathrm{kV})$

\begin{tabular}{|c|c|c|c|c|c|c|c|}
\hline \multicolumn{3}{|c|}{$\begin{array}{c}\text { INSTANTE DE } \\
\text { FECHAMENTO } \\
\text { DAS CHAVES } \\
(\mathrm{ms}) \\
\end{array}$} & \multirow[t]{3}{*}{$\begin{array}{c}\text { JANELA } \\
\text { DE } \\
\text { DADOS } \\
\text { MÓVEIS }\end{array}$} & \multicolumn{4}{|c|}{ TENSÃO (kV) } \\
\hline \multicolumn{3}{|c|}{ FASES } & & 116,0 & 116,5 & 117,0 & 118,0 \\
\hline $\mathrm{A}$ & $\mathrm{B}$ & $\mathrm{C}$ & & Resposta Obtida & Resposta Obtida & Resposta Obtida & Resposta Obtida \\
\hline \multirow{3}{*}{6} & \multirow{3}{*}{6} & \multirow{3}{*}{6} & $1^{a}$ & 0,001015 & 0,001014 & 0,000989 & 0,000971 \\
\hline & & & $2^{\mathrm{a}}$ & 0,000667 & 0,000689 & 0,000711 & 0,000759 \\
\hline & & & $3^{\mathrm{a}}$ & 0,001728 & 0,001856 & 0,001985 & 0,002277 \\
\hline \multirow{3}{*}{6} & \multirow{3}{*}{6} & \multirow{3}{*}{10} & $1^{a}$ & 0,000045 & 0,000044 & 0,000043 & 0,000042 \\
\hline & & & $2^{a}$ & 0,000059 & 0,000057 & 0,000057 & 0,000055 \\
\hline & & & $3^{a}$ & 0,000289 & 0,000291 & 0,000295 & 0,000301 \\
\hline \multirow{3}{*}{6} & \multirow{3}{*}{7} & \multirow{3}{*}{6} & $1^{a}$ & 0,000739 & 0,000714 & 0,000704 & 0,000675 \\
\hline & & & $2^{a}$ & 0,000304 & 0,000313 & 0,000323 & 0,000345 \\
\hline & & & $3^{\mathrm{a}}$ & 0,000469 & 0,000499 & 0,000523 & 0,000585 \\
\hline \multirow{3}{*}{6} & \multirow{3}{*}{7} & \multirow{3}{*}{10} & $1^{\mathrm{a}}$ & 0,000038 & 0,000036 & 0,000035 & 0,000033 \\
\hline & & & $2^{a}$ & 0,000028 & 0,000028 & 0,000028 & 0,000027 \\
\hline & & & $3^{\mathrm{a}}$ & 0,000058 & 0,000058 & 0,000058 & 0,000058 \\
\hline \multirow{3}{*}{6} & \multirow{3}{*}{9} & \multirow{3}{*}{12} & $1^{\mathrm{a}}$ & 0,000170 & 0,000164 & 0,000156 & 0,000144 \\
\hline & & & $2^{\mathrm{a}}$ & 0,000156 & 0,000151 & 0,000144 & 0,000133 \\
\hline & & & $3^{\mathrm{a}}$ & 0,000275 & 0,000266 & 0,000251 & 0,000232 \\
\hline \multirow{3}{*}{6} & \multirow{3}{*}{11} & \multirow{3}{*}{15} & $1^{\mathrm{a}}$ & 0,001035 & 0,001034 & 0,001034 & 0,001034 \\
\hline & & & $2^{a}$ & 0,001037 & 0,001037 & 0,001037 & 0,001038 \\
\hline & & & $3^{a}$ & 0,001096 & 0,001106 & 0,001115 & 0,001137 \\
\hline \multirow{3}{*}{7} & \multirow{3}{*}{9} & \multirow{3}{*}{11} & $1^{\mathrm{a}}$ & 0,000095 & 0,000090 & 0,000086 & 0,000078 \\
\hline & & & $2^{a}$ & 0,000055 & 0,000053 & 0,000052 & 0,000049 \\
\hline & & & $3^{a}$ & 0,000078 & 0,000078 & 0,000078 & 0,000078 \\
\hline \multirow{3}{*}{7} & \multirow{3}{*}{11} & \multirow{3}{*}{7} & $1^{a}$ & 0,000892 & 0,000912 & 0,000921 & 0,000965 \\
\hline & & & $2^{a}$ & 0,000310 & 0,000311 & 0,000308 & 0,000308 \\
\hline & & & $3^{\mathrm{a}}$ & 0,000088 & 0,000088 & 0,000086 & 0,000085 \\
\hline \multirow{3}{*}{7} & \multirow{3}{*}{11} & & $1^{\mathrm{a}}$ & 0,000255 & 0,000247 & 0,000236 & 0,000219 \\
\hline & & 12 & $2^{a}$ & 0,000191 & 0,000185 & 0,000177 & 0,000164 \\
\hline & & & $3^{a}$ & 0,000299 & 0,000292 & 0,000283 & 0,000256 \\
\hline
\end{tabular}

diferencial, considerando inicialmente a primeira janela de dados. A fim de obter maior precisão na resposta, uma segunda janela de dados é usada para a confirmação da resposta anterior. A tabela 8 mostra o desempenho do relé para uma falta interna em $10 \%$ do enrolamento do transformador. Esta tabela indica o tempo gasto pelo algoritmo na detecção da corrente diferencial, classificação pela RNA, bem como o tempo total gasto para gerar o sinal de trip.

A tabela 9 ilustra os tempos gastos pelo relé detectando situações de energização do transformador. Deve ser enfatizado que, para este caso, nenhum sinal de trip foi produzido. A tabela 10 mostra casos relacionados a faltas externas monofásicas e a tabela 11 ilustra os casos correspondentes às faltas externas trifásicas. Observa-se que nenhuma corrente diferencial foi detectada pelo relé nestes casos. A mesma resposta foi obtida para os casos de remoção de falta externa monofásica (tabela 12), remoção de falta externa trifásica (tabela 13) e casos de rejeição de carga (tabela 14), atestando a eficiência do algoritmo proposto.
Tabela 6: Saída da RNA para faltas internas em $10 \%$ do enrolamento do transformador

\begin{tabular}{|c|c|c|c|c|}
\hline \multirow{4}{*}{$\begin{array}{c}\text { ÂNGULO DE } \\
\text { INCIDÊNCIA } \\
\text { (graus) }\end{array}$} & \multirow{4}{*}{$\begin{array}{c}\text { JANELA DE } \\
\text { DADOS MÓVEIS }\end{array}$} & \multicolumn{3}{|c|}{ TENSÃO $=115,0 \mathrm{kV}$} \\
\hline & & \multicolumn{3}{|c|}{ CARGA (MVA) } \\
\hline & & 8 & 10 & 12 \\
\hline & & Resposta Obtida & Resposta Obtida & Resposta Obtida \\
\hline \multirow{3}{*}{43} & $\overline{1^{\mathrm{a}}}$ & 0,999975 & 0,999976 & 0,999976 \\
\hline & $2^{a}$ & 0,999931 & 0,999931 & 0,999931 \\
\hline & $3^{a}$ & 0,999974 & 0,999972 & 0,999971 \\
\hline \multirow{3}{*}{65} & $1^{a}$ & 0,999365 & 0,999379 & 0,999390 \\
\hline & $2^{a}$ & 0,998944 & 0,998944 & 0,998944 \\
\hline & $3^{a}$ & 0,998942 & 0,998942 & 0,998942 \\
\hline \multirow{3}{*}{108} & $1^{\mathrm{a}}$ & 0,998943 & 0,998943 & 0,998943 \\
\hline & $2^{a}$ & 0,998942 & 0,998942 & 0,998942 \\
\hline & $3^{a}$ & 0,998942 & 0,998942 & 0,998942 \\
\hline \multirow{3}{*}{173} & $1^{a}$ & 0,998942 & 0,998942 & 0,998942 \\
\hline & $2^{\mathrm{a}}$ & 0,998946 & 0,998946 & 0,998946 \\
\hline & $3^{a}$ & 0,999019 & 0,999018 & 0,999018 \\
\hline \multirow{3}{*}{216} & $1^{\mathrm{a}}$ & 0,999761 & 0,999755 & 0,999749 \\
\hline & $2^{a}$ & 1,000000 & 1,000000 & 1,000000 \\
\hline & $3^{a}$ & 1,000000 & 1,000000 & 1,000000 \\
\hline \multirow{3}{*}{238} & $1^{a}$ & 0,999995 & 0,999996 & 0,999996 \\
\hline & $2^{a}$ & 0,999919 & 0,999920 & 0,999920 \\
\hline & $3^{a}$ & 0,999977 & 0,999974 & 0,999973 \\
\hline \multirow{3}{*}{260} & $1^{\mathrm{a}}$ & 1,000000 & 1,000000 & 1,000000 \\
\hline & $2^{a}$ & 1,000000 & 1,000000 & 1,000000 \\
\hline & $3^{a}$ & 1,000000 & 1,000000 & 1,000000 \\
\hline \multirow{3}{*}{281} & $1^{\mathrm{a}}$ & 1,000000 & 1,000000 & 1,000000 \\
\hline & $2^{a}$ & 1,000000 & 1,000000 & 1,000000 \\
\hline & $3^{a}$ & 0,999991 & 0,999992 & 0,999992 \\
\hline \multirow{3}{*}{324} & $1^{a}$ & 0,999996 & 0,999996 & 0,999997 \\
\hline & $2^{a}$ & 0,999929 & 0,999929 & 0,999929 \\
\hline & $3^{\mathrm{a}}$ & 0,999930 & 0,999930 & 0,999930 \\
\hline
\end{tabular}

\section{CONCLUSÕES}

Através de observações teóricas e experimentais em publicações na área, destaca-se a especial atenção necessária à detecção da corrente de magnetização (inrush) em sistemas de proteção de transformadores de potência. As eventuais falhas na proteção digital de transformadores ocorrem principalmente devido à inabilidade dos algoritmos atuais em diferenciar precisamente situações faltosas de situações de energização. Este trabalho desenvolve um mecanismo de detecção de correntes de inrush através da diferenciação entre sua forma de onda e a da corrente de falta interna. Isto é conseguido adicionando-se elementos de inteligência artificial ao algoritmo de proteção digital pela utilização de uma rede neural artificial.

Após o processo de treinamento e testes das redes neurais, a melhor estrutura obtida e apresentada neste trabalho a fim de diferenciar as correntes de inrush daquelas de faltas internas ao transformador foi a rede de topologia $12+3+1$, conseguindo convergência mais rápida e resultados de testes precisos. Várias redes neu- 
Tabela 7: Saída da RNA para faltas internas em $90 \%$ do enrolamento do transformador

\begin{tabular}{|c|c|c|c|c|}
\hline \multirow{3}{*}{$\begin{array}{c}\text { ÂNGULO DE } \\
\text { INCIDÊNCIA } \\
\text { (graus) }\end{array}$} & \multirow{3}{*}{$\begin{array}{c}\text { JANELA DE } \\
\text { DADOS MÓVEIS }\end{array}$} & \multicolumn{3}{|c|}{$\begin{array}{c}\text { TENSÃO }=115,0 \mathrm{kV} \\
\text { CARGA (MVA) }\end{array}$} \\
\hline & & 8 & 10 & 12 \\
\hline & & Resposta Obtida & Resposta Obtida & Resposta Obtida \\
\hline \multirow{3}{*}{43} & $1^{\mathrm{a}}$ & 0,999503 & 0,999471 & 0,999435 \\
\hline & $2^{\mathrm{a}}$ & 0,999978 & 0,999978 & 0,999978 \\
\hline & $3^{\mathrm{a}}$ & 0,999935 & 0,999935 & 0,999935 \\
\hline \multirow{3}{*}{65} & $1^{\mathrm{a}}$ & 0,999952 & 0,999952 & 0,999952 \\
\hline & $2^{\mathrm{a}}$ & 0,999930 & 0,999930 & 0,999930 \\
\hline & $3^{\mathrm{a}}$ & 0,999928 & 0,999928 & 0,999928 \\
\hline \multirow{3}{*}{108} & $1^{\mathrm{a}}$ & 0,999908 & 0,999908 & 0,999907 \\
\hline & $2^{\mathrm{a}}$ & 0,999927 & 0,999927 & 0,999927 \\
\hline & $3^{\mathrm{a}}$ & 0,999928 & 0,999928 & 0,999928 \\
\hline \multirow{3}{*}{173} & $1^{\mathrm{a}}$ & 0,999383 & 0,999386 & 0,999381 \\
\hline & $2^{\mathrm{a}}$ & 0,999846 & 0,999846 & 0,999845 \\
\hline & $3^{\mathrm{a}}$ & 0,999995 & 0,999994 & 0,999994 \\
\hline \multirow{3}{*}{216} & $1^{\mathrm{a}}$ & 0,999368 & 0,999371 & 0,999373 \\
\hline & $2^{\mathrm{a}}$ & 0,999554 & 0,999551 & 0,999550 \\
\hline & $3^{\mathrm{a}}$ & 1,000000 & 1,000000 & 1,000000 \\
\hline \multirow{3}{*}{238} & $1^{\mathrm{a}}$ & 0,999350 & 0,999349 & 0,999350 \\
\hline & $2^{\mathrm{a}}$ & 0,999998 & 0,999998 & 0,999998 \\
\hline & $3^{\mathrm{a}}$ & 1,000000 & 1,000000 & 1,000000 \\
\hline \multirow{3}{*}{260} & $1^{a}$ & 0,999998 & 0,999997 & 0,999997 \\
\hline & $2^{\mathrm{a}}$ & 1,000000 & 1,000000 & 1,000000 \\
\hline & $3^{\mathrm{a}}$ & 1,000000 & 1,000000 & 1,000000 \\
\hline \multirow{3}{*}{281} & $1^{\mathrm{a}}$ & 0,999915 & 0,999921 & 0,999924 \\
\hline & $2^{\mathrm{a}}$ & 0,999729 & 0,999729 & 0,999728 \\
\hline & $3^{\mathrm{a}}$ & 0,999612 & 0,999613 & 0,999609 \\
\hline \multirow{3}{*}{324} & $1^{a}$ & 0,997307 & 0,997160 & 0,997000 \\
\hline & $2^{\mathrm{a}}$ & 0,999921 & 0,999921 & 0,999921 \\
\hline & $3^{\mathrm{a}}$ & 0,999930 & 0,999930 & 0,999930 \\
\hline
\end{tabular}

Tabela 8: Desempenho do relé para faltas internas em $10 \%$ do enrolamento do transformador

\begin{tabular}{|c|c|c|c|c|}
\hline \multirow{2}{*}{$\begin{array}{c}\text { ÂNGULO } \\
\text { DE } \\
\text { INCIDÊNCIA } \\
\text { (graus) }\end{array}$} & \multicolumn{4}{|c|}{$\begin{array}{c}\text { TENSÂO }=115 \mathrm{kV} \\
\text { CARGA }=8 \mathrm{MVA} \\
\text { FALTA EM } 10 \% \text { DO ENROLAMENTO }\end{array}$} \\
\hline & $\begin{array}{c}\text { TEMPO DE } \\
\text { DETECÇÃO DE } \\
\text { CORR. DIFER. } \\
\text { PELO RELÉ (ms) }\end{array}$ & $\begin{array}{c}\text { TEMPO DE } \\
\text { CLASSIFICAÇÃO } \\
\text { DA RNA } \\
\text { (ms) }\end{array}$ & $\begin{array}{l}\text { № DE JANELAS } \\
\text { UTILIZADAS NA } \\
\text { CLASSIFICAÇÃO }\end{array}$ & $\begin{array}{c}\text { TEMPO TOTAL } \\
\text { GASTO PELO } \\
\text { ALGORITMO } \\
(\mathrm{ms})\end{array}$ \\
\hline 43 & 1,0 & 5,0 & 2,0 & 6,0 \\
\hline 65 & 1,0 & 5,0 & 2,0 & 6,0 \\
\hline 108 & 1,0 & 5,0 & 2,0 & 6,0 \\
\hline 173 & 1,0 & 5,0 & 2,0 & 6,0 \\
\hline 216 & 1,0 & 5,0 & 2,0 & 6,0 \\
\hline 238 & 1,0 & 5,0 & 2,0 & 6,0 \\
\hline 260 & 1,0 & 5,0 & 2,0 & 6,0 \\
\hline 281 & 1,0 & 5,0 & 2,0 & 6,0 \\
\hline 324 & 1,0 & 5,0 & 2,0 & 6,0 \\
\hline
\end{tabular}

rais distinguiram com exatidão as situações onde o relé deveria ou não operar, isto é, os casos de falta interna ao transformador ou os casos de energização, com $100 \%$ de acertos, porém a rede de topologia $12+3+1$ foi escolhida por ser a de estrutura mais simples. Foi ainda aplicado um estudo sobre o algoritmo de operação do relé com a inclusão da rede neural artificial escolhida, em
Tabela 9: Desempenho do relé para energização do transformador

\begin{tabular}{|c|c|c|c|c|c|c|}
\hline \multirow{3}{*}{\multicolumn{3}{|c|}{$\begin{array}{c}\text { INSTANTE DE } \\
\text { FECHAMENT } \\
\text { DAS CHAVES } \\
(\mathrm{ms})\end{array}$}} & \multirow{2}{*}{\multicolumn{4}{|c|}{ TENSÃO = 114,0 kV }} \\
\hline & & & & & & \\
\hline & & & \multirow{3}{*}{$\begin{array}{c}\text { TEMPO DE } \\
\text { DETECÇÃO D } \\
\text { CORR. DIFE } \\
\text { PELO RELÉ (m }\end{array}$} & \multirow{3}{*}{\begin{tabular}{|c|} 
TEMPO DE \\
ELASSIFICAÇ \\
DA RNA \\
s) $\quad(\mathrm{ms})$
\end{tabular}} & \multirow{3}{*}{$\begin{array}{l}\text { № DE JANELA } \\
\text { QJTILIZADAS } \\
\text { CLASSIFICAÇ }\end{array}$} & \multirow{3}{*}{$\begin{array}{c}\text { STEMPO TOTA } \\
\text { A GASTO PEL } \\
\text { O ALGORITMO } \\
(\mathrm{ms})\end{array}$} \\
\hline \multicolumn{3}{|c|}{ FASES } & & & & \\
\hline$A$ & $\mathrm{~B}$ & $\mathrm{C}$ & & & & \\
\hline 6 & 6 & 6 & 2,0 & 5,0 & 2,0 & 7,0 \\
\hline 6 & 6 & 10 & 1,0 & 5,0 & 2,0 & 6,0 \\
\hline 6 & 7 & 6 & 2,0 & 5,0 & 2,0 & 7,0 \\
\hline 6 & 7 & 10 & 1,0 & 5,0 & 2,0 & 6,0 \\
\hline 6 & 9 & 12 & 1,0 & 5,0 & 2,0 & 6,0 \\
\hline 6 & 11 & 15 & 1,0 & 5,0 & 2,0 & 6,0 \\
\hline 7 & 9 & 11 & 2,0 & 5,0 & 2,0 & 7,0 \\
\hline 7 & 11 & 7 & 1,0 & 5,0 & 2,0 & 6,0 \\
\hline 7 & 11 & 12 & 2,0 & 5,0 & 2,0 & 7,0 \\
\hline 7 & 6 & 9 & 2,0 & 5,0 & 2,0 & 7,0 \\
\hline 7 & 7 & 6 & 2,0 & 5,0 & 2,0 & 7,0 \\
\hline 7 & 7 & 7 & 2,0 & 5,0 & 2,0 & 7,0 \\
\hline 9 & 9 & 13 & 2,0 & 5,0 & 2,0 & 7,0 \\
\hline 9 & 10 & 13 & 2,0 & 5,0 & 2,0 & 7,0 \\
\hline 9 & 6 & 6 & 2,0 & 5,0 & 2,0 & 7,0 \\
\hline 9 & 9 & 12 & 2,0 & 5,0 & 2,0 & 7,0 \\
\hline 9 & 7 & 10 & 2,0 & 5,0 & 2,0 & 7,0 \\
\hline 9 & 11 & 7 & 1,0 & 5,0 & 2,0 & 6,0 \\
\hline
\end{tabular}

Tabela 10: Desempenho do relé para falta externa monofásica

\begin{tabular}{|c|c|c|}
\hline \multirow{3}{*}{$\begin{array}{l}\text { ÂNGULO DE } \\
\text { INCIDÊNCIA DA } \\
\text { FALTA NA } \\
\text { FASE A } \\
\text { (graus) }\end{array}$} & \multicolumn{2}{|c|}{ TENSÃO (kV) } \\
\hline & 112,7 & 115,0 \\
\hline & $\begin{array}{c}\text { DETECÇĀO DE } \\
\text { CORRENTE } \\
\text { DIFERENCIAL }\end{array}$ & $\begin{array}{l}\text { DETECÇÃO DE } \\
\text { CORRENTE } \\
\text { DIFERENCIAL }\end{array}$ \\
\hline 43 & NÁO & NĀO \\
\hline 173 & NẤO & NÂOO \\
\hline 216 & NÄO & NÃO \\
\hline 281 & NẪO & NẪO \\
\hline 324 & NÂO & NÁO \\
\hline
\end{tabular}

substituição ao processo de filtragem para a obtenção do conteúdo harmônico do sinal, avaliando o funcionamento total do dispositivo. O sistema obteve respostas corretas para os vários tipos de situações testadas, contando com uma classificação rápida e precisa por parte da RNA. Com relação ao programa SNNS, a maior limitação encontrada por esta ferramenta foi a dificuldade em aplicar-se os algoritmos de treinamento com parâmetros variáveis no decorrer do processo usando-se apenas a interface gráfica do simulador de redes neurais. Isto foi superado pela obtenção de estruturas neurais de rápida convergência e, assim, não foi necessária nessa etapa a variação de parâmetros tais como a taxa de aprendiza- 
Tabela 11: Desempenho do relé para falta externa trifásica

\begin{tabular}{|c|c|c|}
\hline \multirow{3}{*}{$\begin{array}{l}\text { ÂNGULO DE } \\
\text { INCIDÊNCIA DA } \\
\text { FALTA } \\
\text { TRIFÁSICA } \\
\text { (graus) }\end{array}$} & \multicolumn{2}{|c|}{ TENSÃO (kV) } \\
\hline & 112,7 & 115,0 \\
\hline & $\begin{array}{l}\text { DETECÇÃO DE } \\
\text { CORRENTE } \\
\text { DIFERENCIAL }\end{array}$ & $\begin{array}{c}\text { DETECÇÃO DE } \\
\text { CORRENTE } \\
\text { DIFERENCIAL }\end{array}$ \\
\hline 43 & NÃO & NÃO \\
\hline 173 & NÃO & $\mathrm{NÃO}$ \\
\hline 216 & NÃO & NÃO \\
\hline 281 & NÃO & NÃO \\
\hline 324 & $\mathrm{NÃO}$ & NÃO \\
\hline
\end{tabular}

Tabela 12: Desempenho do relé na remoção de falta externa monofásica

\begin{tabular}{|c|c|c|c|c|}
\hline \multirow{3}{*}{$\begin{array}{l}\text { ÂNGULO DE } \\
\text { INCIDÊNCIA DA } \\
\text { FALTA NA } \\
\text { FASE A } \\
\text { (graus) }\end{array}$} & \multicolumn{4}{|c|}{ INSTANTE DE REMOÇÃO DA FALTA (ms) } \\
\hline & 40,0 & 50,0 & 60,0 & 70,0 \\
\hline & $\begin{array}{l}\text { DETECÇÁO DE } \\
\text { CORRENTE } \\
\text { DIFERENCIAL }\end{array}$ & $\begin{array}{c}\text { DETECÇĀO DE } \\
\text { CORRENTE } \\
\text { DIFERENCIAL }\end{array}$ & $\begin{array}{c}\text { DETECÇĀO DE } \\
\text { CORRENTE } \\
\text { DIFERENCIAL }\end{array}$ & $\begin{array}{l}\text { DETECÇÁO DE } \\
\text { CORRENTE } \\
\text { DIFERENCIAL }\end{array}$ \\
\hline 43 & NÁO & NÂO & NÁO & NÁO \\
\hline 173 & NAOO & NAO & NAO & NÁO \\
\hline 281 & NÃO & NÃO & NÄO & NÄO \\
\hline
\end{tabular}

Tabela 13: Desempenho do relé na remoção de falta externa trifásica

\begin{tabular}{|c|c|c|c|c|}
\hline \multirow{3}{*}{$\begin{array}{l}\text { ÂNGULO DE } \\
\text { INCIDÊNCIA DA } \\
\text { FALTA } \\
\text { TRIFÁSICA } \\
\text { (graus) }\end{array}$} & \multicolumn{4}{|c|}{ INSTANTE DE REMOÇÃO DA FALTA (ms) } \\
\hline & 40,0 & 50,0 & 60,0 & 70,0 \\
\hline & $\begin{array}{l}\text { DETECÇĀO DE } \\
\text { CORRENTE } \\
\text { DIFERENCIAL }\end{array}$ & $\begin{array}{c}\text { DETECÇĀO DE } \\
\text { CORRENTE } \\
\text { DIFERENCIAL }\end{array}$ & $\begin{array}{c}\text { DETECÇĀO DE } \\
\text { CORRENTE } \\
\text { DIFERENCIAL }\end{array}$ & $\begin{array}{c}\text { DETECÇĀO DE } \\
\text { CORRENTE } \\
\text { DIFERENCIAL }\end{array}$ \\
\hline 43 & NÂO & NÂO & NÂO & NÂOO \\
\hline 173 & $\overline{N A O O}$ & $\overline{N A \bar{O}}$ & $\overline{N A \bar{O}}$ & $\overline{N A \bar{O}}$ \\
\hline 281 & NĀO & NÂO & NĀO & NÁO \\
\hline
\end{tabular}

Tabela 14: Desempenho do relé para rejeição de carga

\begin{tabular}{|c|c|c|c|c|c|}
\hline \multirow{2}{*}{\multicolumn{3}{|c|}{$\begin{array}{c}\text { INSTANTE DE } \\
\text { REJEIÇÃO DA } \\
\text { CARGA (ms) }\end{array}$}} & \multicolumn{3}{|c|}{ CARGA (MVA) } \\
\hline & & & 8,0 & 10,0 & 12,0 \\
\hline & & & \multirow{3}{*}{$\begin{array}{l}\text { DETECÇÃO DE } \\
\text { CORRENTE } \\
\text { DIFERENCIAL }\end{array}$} & \multirow{3}{*}{$\begin{array}{c}\text { DETECÇÃO DE } \\
\text { CORRENTE } \\
\text { DIFERENCIAL }\end{array}$} & \multirow{3}{*}{$\begin{array}{l}\text { DETECÇÃO DE } \\
\text { CORRENTE } \\
\text { DIFERENCIAL }\end{array}$} \\
\hline \multicolumn{3}{|c|}{ FASES } & & & \\
\hline $\bar{A}$ & $\mathrm{~B}$ & $\mathrm{C}$ & & & \\
\hline 18 & 10 & 15 & NÂO & NÂO & $\mathrm{NÂO}$ \\
\hline 13 & 10 & 18 & NÂO & NÂO & NÂO \\
\hline 24 & 13 & 18 & $\overline{N A ̂ O}$ & NÂO & $\overline{N A ̂ O}$ \\
\hline 15 & 24 & 13 & NÃO & NÂO & NÃO \\
\hline
\end{tabular}

gem e o termo Momentum. Com isso, acompanhou-se a característica de decaimento dos erros de aprendizagem para as estruturas estudadas, observando-se que as respostas das redes para os conjuntos de testes apresentados não demonstraram erros de classificação. De forma geral, conclui-se que o método desenvolvido mostrouse eficiente em busca do objetivo proposto. Um maior complemento do trabalho será ainda conseguido quando dados gerados pelo ATP forem substituídos por valores reais captados através de ensaios em transformadores e a elaboração de um protótipo do relé for iniciada. O efeito de saturação dos dispositivos transformadores de corrente (TCs) poderá constituir parte de estudos futuros.

A aplicação da ferramenta redes neurais artificiais constitui uma nova e importante etapa na metodologia de análise de relés diferenciais na busca de um melhor desempenho da proteção de transformadores de potência.

\section{REFERÊNCIAS}

Alternative Transients Program Rule Book (1987), Leuven EMTP Center.

Bastard, P.; Meunier, M. and H. Regal (1995). Neural Network-based Algorithm for Power Transformer Differential Relays. IEE Proceedings on Generation, Transmission and Distribution, Vol.142, n.4, pp. 386-392.

Bertrand, P.; Martin, E. and M. Guillot (1997). Neural Networks: A Mature Technique for Protection Relays. IEE Conference Publication, n.438, pp. 1.22.11.22 .5 .

Bryson, A.E. and Y. Ho (1969). Applied Optimal Control, Blaisdell.

Carvalho, A.C.P.L.F. ; Braga, A.P. and T.B. Ludermir (1998), Fundamentos de Redes Neurais Artificiais, XI Escola Brasileira de Computação.

Coury, D.V.; Campos, P.G. and M.C. Tavares (1998). Modelling a Power Transformer for Investigation of Digital Protection Schemes. 8th International Conference on Harmonics and Quality of Power (ICHQP'98), pp. 489-494.

Cun, Y. Le (1985). A Learning Procedure for Assymetric Threshold Network. Proceedings of Cognitiva 85, pp. 599-604.

Grcar, B. and D. Dolinar (1994). Integrated Digital Power Transformer Protection. IEE Proceedings on Generation, Transmission and Distribution, vol.141, n.4, pp. 323-328. 
Hebb, D. O (1949). The Organization of Behavior, Wiley.

Hertz, J.; Krogh, A. and R.G. Palmer (1991). Introduction to the Theory of Neural Computation, AdisonWesley Pub. Co.

Hopfield, J. J. (1982). Neural Networks and Physical Systems with Emergent Collective Properties. Proceedings of the National Academy of Sciences, n.79, pp. 2554-2558.

Horowitz, S.H. and A.G. Phadke (1992). Power System Relaying. John Wiley e Sons Inc.

Kasztenny, B.; Rosolowski, E.; Saha, M.M. and B. Hillstrom (1995). A Power Transformer Model for Investigation of Protection Schemes. International Conference on Power Systems Transients (Sept.), pp. 136-141.

Kolla, S.R. (1995). Digital Protection of Power Transformers Using Artificial Neural Networks. Proceedings of $2^{\text {nd }}$ International Conference on Advances in Instrumentation and Control, pp. 141-150.

Ling, P.C.Y. and A. Basak (1989). A New Detection Scheme for Realisation of Magnetising Inrush Current in Transformers. Fourth International Conference on Developments in Power System Protection , pp. 239-243.

Liu, P.; Malik, O.P.; Chen, D.; Hope, G.S. and Y. Guo (1992). Improved Operation of Differential Protection of Power Transformers for Internal Faults. IEEE Transactions on Power Delivery, vol.7, n.4, pp. 1912-1919.

Mao, P.L.; Bo, Z.Q.; Aggarwal, R.K. and R.M. Li (1998). Identification of Electromagnetic Transients in Power Transformer System Using Artificial Neural Network. Proceedings of the 1998 International Conference on Power System Technology, Vol.2, pp. 880-884.

McCulloch, W. S. and W. Pitts (1943). A Logical Calculus of the Ideas Immanent in Nervous Activity. Bulletin of Mathematical Biophysics, n.5, pp. 115133.

Minsky, M. and S. Papert (1969). Perceptrons: an Introduction to Computational Geometry. MIT Press, Massachussets.

Nagpal, M.; Sachdev, M.S.; Ning, K. and L.M. Wedephol (1995). Using a Neural Network for Transformer Protection. Proceedings of the 1995 International Conference on Energy Management and Power Delivery, Part 2, pp. 674-679.
Parker, D. (1985). Learning Logic: Casting the Cortex of the Human Brain in Silicon. Technical Report, Center for Computational Research in Economics and Management Science, MIT.

Perez, L.G., Flechsig, A.J., Meador, J.L. and Z. Obradovic (1994). Training an Artificial Neural Network to Discriminate Between Magnetizing Inrush and Internal Faults. IEEE Transactions on Power Delivery, Vol.9, n.1, pp. 434-441.

Pihler, J.; Grcar, B. and D. Dolinar (1997). Improved Operation of Power Transformer Protection Using Artificial Neural Network. IEEE Transactions on Power Delivery, Vol.2, n.13, pp. 1128-1136.

Rahman, M.A. and B. Jeyasurya (1988). A State-of-theart Review of Transformer Protection Algorithms. IEEE Transactions on Power Delivery, vol.3, n.2, pp. 534-544.

Rosenblatt, F. (1958). The Perceptron: A Probabilistic Model for Information Storage and Organization in the Brain. Psychol. Rev. , n.65, pp. 386-408.

Rumelhart, D. E. and J. L. McClelland (1986). Parallel Distributed Processing, vol.1, The MIT Press.

Rumelhart, D. E., Hinton, G. E. and R. J. Williams (1986). Learning Representations by Backpropagation Errors, Nature, n.323, pp. 533-536.

Sidhu, T.S. and M.S. Sachdev (1992). On-line Identification of Magnetizing Inrush and Internal Faults in Three-Phase Transformers. IEEE Transactions on Power Delivery, vol.7, pp. 1885-1891.

SNNS User Manual (1995). Institute for Parallel and Distributed High Performance Systems, University of Stuttgard.

Verma, H.K. and A.M. Basha (1986). A Microprocessorbased Inrush Restrained Differential Relay for Transformer Protection. Journal of Microcomputer Applications, pp. 313-318.

Werbos, P. (1974). Beyond Regrssion: New Tools for Prediction and Analysis in the Behavioral Sciences, $\mathrm{PhD}$ thesis, Harvard University.

Widrow, B. and M. E. Hoff (1960). Adaptative Switching Circuits. Institute of Radio Engineers, Western Electronic Show and Convention. 